when heated in pure steam at temperatures ranging from $350^{\circ} \mathrm{C}$. upwards. The author concludes that the action of steam on iron takes place in two stages, first, the dissociation of the steam, second, the combination of the dissociated oxygen with the iron and the consequent liberation of free hydrogen gas. If this conclusion is correct, the dissociation pressure of the oxide of iron produced at $350^{\circ} \mathrm{C}$. is of the order of $\mathrm{x} .02 \times 10^{-12}$ atmospheres.

A paper on tests of cast iron was read by Mr. E. Adamson. The general results were as follows. The best tensile and transverse tests are obtained from bars which have been machined. Transverse test bars cast on edge and tested with the "fin " in compression give the best results in testing. The transverse test is not so trustworthy or helpful as that of the moment of resistance. The use of high-grade ferro-silicon in the foundry is of no commercial value. Cast iron gives the best results when poured as hot as possible.

Mr. T. Swinden contributed a paper on the constitution of carbon-tungsten steels. This paper is a continuation of the author's earlier researches on the same subject. His hardness tests and exhaustive microscopic examination support in every respect the conclusions previously recorded upon the cooling-curve work, namely, that the "lowering temperature" marks a definite reaction in which the tungsten is involved, and that the rate of cooling from above the lowering temperature is without influence on the low point. It is suggested that the hypothesis of Edwards, that the lowering of the point is due to the formation of a carbide tungsten, is untenable. The theory of a double carbide formation is difficult to account for with the cooling curve and microscopic facts observed. A tentative hypothesis is given, wherein the lowering of the recalescence point is attributed to the solution of a tungsten compound, probably $\mathrm{Fe}_{3} \mathrm{~W}$, at the lowering temperature. The tungsten is re-precipitated at the low point, and the $\mathrm{Fe}_{i} \mathrm{C}$ immediately separates also.

\section{THE OPENING OF THE LONDON MEDICAL SESSION.}

A LTHOUGH under the present five-years' curriculum of medical study it is perhaps preferable for the student to commence his studies in the summer session, by a time-honoured ordinance the medical year in London always dates from October $\mathbf{r}$ or thereabouts, and is in many of the schools made the occasion for the distribution of prizes and the delivery of addresses of welcome and advice.

At University College Hospital Sir John Tweedy opened the session, and in his address dealt particularly with the importance of the experimental method in medicine. $\mathrm{He}$ pointed out that failure to appreciate the difference between the dissemination of knowledge and the advance of knowledge had given rise to much confusion of thought and not a little waste of endeavour. Perhaps the crudest manifestation of this confusion was the belief, real or feigned, by some persons that inquisitorial experiments are performed in hospitals on men, or on animals, or both. Less crude-nay, even creditable in a sense-was the notion that by establishing sanatoria or endowing special hospitals for the treatment of particular classes of general diseases it was possible to solve the problem of the nature and origin of these diseases and to hasten the discovery of the means of prevention and cure. $\mathrm{He}$ proceeded to give examples of the value of research in combating disease, instancing the discoveries relating to malaria, Malta and vellow fevers, and the arrest of hæmorrhage by the ligature of arteries, the last-named being the outcome of experiments on horses performed by Dr. J. F. D. Jones at the beginning of the last century.

At St.: Mary.'s Hospital, the principal of the University of London; Dr. Miers, gave an address to the students on the importance of "theories." Dr. Miers said that for all people there was a certain period of life when they were ready and anxious to invent and to produce something original. It was in the period including the close of school, life and the beginning of university life, or whatever came after school, that most people had been guilty of attempts to write poetry, or had endeavoured to construct a tale, or had believed themselves to be on the brink of a discovery or invention, or had taken up some new idea or theory of life which was for them, at least, a new thing of their own making and a piece of their own philosophy. It had been too much the fashion to decry youthful efforts, and to endeavour to persuade ourselves that knowledge and experience were required before anything good came out of a man unless he were a heavenborn genius.

After referring to the instances of Pasteur, Darwin, and other great workers in research, the lecturer went on to draw a distinction between the pleasure of merely acquiring knowledge or making observations, and that more intellectual pleasure of scientific discovery. He contended that after school days were over all the preparatory and educational work that they had to do should be taught and learnt in a new spirit, no longer as an exercise or a preparation, but as real active living research guided by the light of theory and inspired with the hope of discovery. He counselled medical students in all their work to adopt a theory and stick to it so long as they were able, and then, if necessary, to invent a new one, to work in the spirit of investigation in the light of their theories, and to regard all their work as belonging to medical science and illustrating the general principles of that science.

At the Middlesex Hospital, after Dr. Goodall, the subdean, had addressed the students on "walking the hospitals," in which he emphasised the importance of the ground-work of chemistry, biology, anatomy, and physiology for the intelligent study of clinical medicine, Lieut. Shackleton distributed the prizes and gave a sketch of some of his experiences in the Antarctic. The temperature of the explorers on the plateau went down to $94^{\circ} \mathrm{F}$. or $93^{\circ}$ F.- four or five degrees below normal-without ill effect. The members of the expedition did not suffer from colds, though on one occasion when a bale of clothing packed in England was opened they caught cold, but it disappeared when they went out, while those who remained in the hut still suffered.

"St. George's and the Progress of Physic" was the title of Dr. Rolleston's opening address at St. George's Hospital. The lecturer detailed many interesting facts in the lives of Matthew Baillie (physician to the hospital, $1-87-1800)$. who did much for the study of anatomy; Thomas Young (physician, $181 \mathrm{r}-29$ ), best known as the discoverer of the undulatory theory of light; John Hunter, the great anatomist and physiologist; Sir Benjamin Brodie, the well-known surgeon; and Edward Jenner, the discoverer of vaccination.

At the London School of Medicine for Women, Mrs. Garrett Anderson, M.D., in opening the proceedings, referred to the admission of Miss Woodward to the membership of the Royal College of Physicians.

Mrs. Henry Fawcett, LL.D., gave an address on "pioneering," in which she pointed out the courage and self-sacrifice displayed by the pioneer in every branch of human endeavour. The pioneers cleared away difficulties, made the road for those who followed safe and easy. If they really wished to recognise with gratitude the work which had been done for them by the great pioneers, she would wish nothing better for them than that they might be able to claim, even though they might not receive, the gratitude of those who followed after them in the noble profession to which they were devoting their lives.

\section{FORTHCOMING BOOKS OF SCIENCE. Agriculture.}

Constable and Co., Ltd.-Soils and Manures, J. A. Murray, illustrated.

Wm. Blackwood and Sons.-The Life and Times of Akhnaton, Pharaoh of Egypt, A. E. P. Weigall, illustrated. Constable and Co., Ltd.-The Tomb of Queen Tiyi (Theodore M. Davis's Excavations), illustrated. Macmillan and Co., Ltd.-Totemism and Exogamy: a Treatise on Certain Ancient Forms of Superstition and Society, Dr. J. G. Frazer, 3 vols. Swan Sonnenschein and Co., Ltd.-Bushman Folk-lore, Miss L. C. Lloyd, edited by Dr. G. M. Theal, illustrated; History No. 2084 , VOL. $8 \mathrm{I}$ ] 